ideal from the perspective of public health and disease prevention. ${ }^{13}$ Evidence from large-scale cross-sectional and retrospective population studies reveals some startling results in China: less than a quarter $(22 \%)$ of school students engage in any type of daily physical activity that lasts 60 min or more, ${ }^{14}$ with a general downward trend ${ }^{15} ; 85.8 \%$ engage in sedentary behaviours longer than 2 hours per day, ${ }^{16}$ leading to a decline in physical fitness, ${ }^{17}$ with only 3 in 10 students achieving an 'excellent' or 'good' rating in national physical fitness standards ${ }^{18}$; and only 15\%-34\% meet recommended physical activity guidelines. ${ }^{11} 1920$ Overall, there is an extremely low prevalence $(0.5 \%)$ of ideal cardiovascular health as reflected by seven health metrics, namely smoking, body mass index (BMI), dietary intake, physical activity, blood pressure, blood glucose and total cholesterol. $^{21}$

The persistent trend in low levels of physical activity and achievement in meeting physical fitness standards among Chinese children and adolescents has been accompanied by a high prevalence of sedentary behaviours exhibited outside school environments, a situation made worse by excess dietary calorie intake, and has contributed to an associated epidemic of obesity. Nationally, between 2016 and 2017, 35\%-37\% of children and adolescents reported spending more than 2 hours per day on electronic screens (ie, the amount of time spent interacting with TVs, computers, smartphones, digital tablets and video games), ${ }^{20} 22$ and, more seriously, between 1995 and 2014, this youth population saw a fourfold increase in overweight and obesity, with around 1 in 5 children and adolescents being either overweight or obese. ${ }^{23}$ This time period coincides with an increased globalisation of China and reflects changes in food availability and electronic media, both of which contribute to overweight, obesity and sedentary behaviours. It is projected that the prevalence of childhood overweight and obesity will reach $28 \%$ (or 49.5 million children) by $2030 .{ }^{24}$ This epidemic of obesity, if it continues and no preventive measures are taken, will raise serious public health concerns because school-aged children and adolescents who have high BMIs and excessive body weights are known to be at high risk of developing other health problems, including cardiovascular, metabolic and musculoskeletal diseases, ${ }^{25}$ as well as depression. ${ }^{26}$

Despite the importance of regular physical activity and compelling evidence from the growing body of scientific literature regarding its health benefits for children and adolescents, there has been a lack of research-driven, evidence-based, culturally relevant consensus on physical activity and health in China. The absence of this may hinder the nation's public health efforts in preventing chronic diseases and promoting healthy growth for millions of Chinese children and adolescents. This population also bears the mounting health burden of non-communicable disease risk factors, ${ }^{27-29}$ has a high prevalence of depressive symptoms or major depressive disorders ${ }^{30-32}$ and experiences high expectations and pressure in achieving academic excellence $e^{33} 34$ that is both culturally embedded and potentially health debilitating. If not addressed in a timely way, this crisis will undermine China's target goal of having 50\% of its youth achieve 'excellent' performance in physical fitness by 2022 and $60 \%$ by $2030 . .^{35}$

This consensus statement is therefore aimed at narrowing the significant gaps in our current knowledge, addressing the need for better strategic policies and providing impetus for public health and research that will revive China's efforts in promoting physical activity and fitness among children and adolescents. Our aim aligns with the international effort to develop guidelines on physical activity and sedentary behaviours for children and adolescents ${ }^{36-38}$ and contributes to the global efforts in promoting physical activity among youth populations as a primary preventive measure for combatting non-communicable diseases, including childhood obesity.

The consensus includes an overview of the current national and international physical activity guidelines for young people ${ }^{39}$ that serve as a principal premise for the consensus, including those issued by the WHO and other leading countries. This overview is followed by a description of the objectives and processes from which the current consensus was developed. The paper then organises the consensus into major themes linking physical activity with health in child and adolescent populations. It also describes (A) practical challenges and barriers inherent in promoting physical activity in China, (B) research needs and gaps, (C) major public health messages, and (D) the significance of this accord as part of international efforts in reducing sedentary behaviours and increasing physical activity among schoolaged children and adolescents. It concludes with a call for the development of effective evidence-based, culturally appropriate policies and interventions for Chinese children and adolescents.

\section{PHYSICAL ACTIVITY GUIDELINES}

Current international guidelines ${ }^{40-44}$ on physical activity for children and adolescents (age range: 5-17 years) generally recommend an active lifestyle and encourage participation in daily physical activity, including both light-intensity and moderate to vigorous-intensity physical activities, with the latter intensity being commonly recommended because it is more favourably related to a variety of health outcomes in children and youth. ${ }^{12}$ Key guidelines include the following:

- Aerobic physical activity: Most of the $60 \mathrm{~min}$ or more per day should be either moderate-intensity or vigorous-intensity aerobic physical activity and should include vigorousintensity physical activity at least 3 days a week.

- Muscle-strengthening physical activity: As part of their 60 min or more of daily physical activity, children and adolescents should include muscle-strengthening physical activity at least 3 days a week.

- Bone-strengthening physical activity: As part of their $60 \mathrm{~min}$ or more of daily physical activity, children and adolescents should include bone-strengthening physical activity at least 3 days a week.

Guidelines recommend that the amount of physical activity be greater than $60 \mathrm{~min}$ if additional health benefits are to be gained. Current guidelines also emphasise the need for creating physical activities that are age appropriate for children and adolescents, enjoyable and varied. ${ }^{45}$ As research continues, new paradigms related to activity and health are emerging. For example, the Canadian 24-Hour Movement Guidelines ${ }^{42} 46$ have been proposed that integrate the balance of time spent per day in light to vigorous-intensity physical activity, sedentary behaviours and sleep to enhance health outcomes in those aged 5-17 years.

However, motivation and compliance for actively engaging in (or changing) health-related behaviours are significantly impacted by sociocultural standards and traditions. Although the science underlying current guidelines may be compelling, generally it has been derived from a narrow set of populations (primarily North American and European) and it is unlikely to drive wide-scale changes in activity behaviour in other cultures. Thus, it is critically important for public health and physical education agencies developing activity and health guidelines for China to fully recognise that science filtered through cultural considerations is fundamental for any implementation to be 
effective. Finally, following the same reasoning, the outcomes of any activity and health-focused guidelines for China must parallel the targets outlined in the national policy Healthy China 2030.

\section{OBJECTIVES AND PROCESS OF CONSENSUS DEVELOPMENT Objectives}

The objective of this paper is to develop an evidence-based, best-practices consensus aimed at promoting physical activity among Chinese school-aged children and adolescents between the ages of 6 and 17 years. ${ }^{47}$ This objective supports the Healthy China 2030 Action Plan $^{35}$ and creates a scientific foundation for designing and developing culturally appropriate and populationspecific guidelines, initiatives, interventions and strategies that can be used by schools, families, clinics and communities to increase physical activity and improve physical fitness among this youth population.

\section{Panel of experts and consensus process}

A steering committee $(n=4)$ was formed that was tasked with (A) conducting a literature search and review on physical activity and health for children and adolescents; (B) identifying key topic areas to be considered in the consensus; and (C) drafting the initial consensus. The consensus was then reviewed by an expanded panel of experts $(n=16)$ who were carefully selected to balance experience and expertise in the areas of public health, physical activity, epidemiology, physical fitness, physical education, paediatrics and exercise physiology, and to ensure diversity in themes and viewpoints in the statement. Systematic reviews were used as primary literature sources when available (see below). The writing group engaged in frequent email exchanges, conference calls, reviews of the literature and written communications. From this background work, an initial version of the consensus statement was drafted by the working committee and subsequently shared with panel members and an extended group of international experts in the field of physical activity and sports. The final version of the consensus document was developed based on input and comments from all participating members.

\section{Physical activity and physical activity intensity defined}

Consistent with the general public health model of promoting physical activity, which is defined as any bodily movement produced by skeletal muscles that requires energy expenditure, ${ }^{348}$ the consensus focused on the health benefits of regular physical activity, which, by definition, includes structured and unstructured forms of physical activity, as well as leisure, sports and transport activities, conducted in settings both in school and outside school.

Physical activity intensity refers to the activity's metabolic equivalent (MET), a term used to represent the rate of energy expenditure required to perform any physical activity. ${ }^{3}$ A MET is defined as the ratio of an activity-specific metabolic rate to the estimated resting metabolic rate (RMR; the energy the body needs to function while at rest). The absolute amount of energy expended to complete a physical task is a function of the type and intensity of an activity. In child and adolescent populations, the energy cost of an activity also varies with age and maturation status. Accordingly, MET values in youth are referred to a youth MET, which represents MET values specific to a given age group. ${ }^{4 乌}$ Currently, the precise $\mathrm{MET}_{\mathrm{y}}$ intensity cut-points in energy expenditure have not been operationally defined. Based on using the RMR as a baseline MET value, intensity can be classified into: sedentary behaviours $(\leq 1.50 \mathrm{MET}$ for activities such as reading, internet, TV and board games); light-intensity physical activity (1.51-2.99 MET for activities such as active video games, quiet school work and slow walking); moderateintensity physical activity (3.00-5.99 $\mathrm{MET}_{\mathrm{y}}$ for activities such as callisthenics, household chores and volleyball); and vigorousintensity physical activity $(\geq 6.00 \mathrm{MET}$ for activities such as cycling, running, soccer and basketball). ${ }^{50}$ (For the comprehensive list of activities and their associated MET for children and youth aged 6-18 years, visit www.nccor.org/tools-youthcompendium.)

\section{Sources of evidence}

The themes in the consensus statement are drawn from a wide range of research articles gathered from the fields of epidemiology, medicine, physiology, neuroscience and sociopsychology. The collection of these articles, both in English and Chinese, was based on an extensive electronic search of the literature using the following databases: EBSCO (Academic Search Complete, CINAHL Plus, MEDLINE, PsycINFO, SportDISCUS), CNKI, PubMed, Cochrane Library, EMBASE, SinoMed and Web of Science. No restrictions were imposed with regard to publication date. The consensus statement was developed using an expert consensus development approach involving group decisionmaking according to guidelines and other guideline documents ${ }^{51}$ (eg, expert consensus statements) published by national and international authorities (eg, WHO), as well as peer-reviewed literature.

Using their best judgement, the steering committee members selected individual studies, systematic reviews, consensus statements and meta-analyses that provided the best evidence available on the topic. Major individual research studies included those using cross-sectional, short and long-term populationbased observational and/or prospective designs and randomised controlled intervention designs that involved school-aged children and adolescents, recognising the strengths and limitations of each of the research strategies. Studies on children with chronic disease conditions or disabilities were excluded. The main search was conducted on 1 January 2019, and the latest search was performed on 25 February 2020 (see online supplementary file). The search from the electronic databases resulted in a total of 17851 potential articles. On screening for relevance, 81 articles were included in this consensus.

\section{Themes}

The resulting consensus statement presents the panel's consensus reached on the effects and associations of physical activity on multiple health outcomes in children and adolescents, including cardiovascular fitness, brain health, physical and mental health and academic achievement. The statement also presents the panel's consensus on various individual factors, socioeconomic status, the built environment and physical factors, intervention strategies and risk of injuries from participation in physical activities that have been shown to impact or influence physical activity levels or health in the youth population.

\section{STATEMENTS}

\section{Theme 1: overall health}

1. An average of at least $60 \mathrm{~min}$ of moderate-intensity physical activity per day promotes the overall health of children and adolescents. Being physically active is essential because it contributes to the physical, cognitive, social and emotional well-being of children and adolescents ${ }^{35253}$ and increases the 
odds that they will stay physically active and healthy during adulthood. ${ }^{5455}$

2. In contrast, being sedentary or engaging only in lightintensity physical activity can contribute to the development of adverse health conditions among children and adolescents $^{356}$; low cardiorespiratory and muscular fitness; insulin resistance and type 2 diabetes; low bone mass, bone structure and bone strength; and an increased risk of cardiovascular disease, including hyperlipidaemia (eg, high levels of triglyceride) and high blood pressure. With excess calorie intake, it can also lead to a positive energy balance ${ }^{57}$ contributing to overweight and obesity, which are risk factors for type 2 diabetes.

3. A high level of physical activity and cardiorespiratory fitness in childhood may play an important role in protecting health later in life. ${ }^{5}$

\section{Theme 2: cardiorespiratory fitness and health}

1. Adolescents who have low levels of cardiorespiratory fitness have an increased risk of cardiovascular diseases (ie, high cholesterol, low high-density lipoprotein cholesterol, impaired glucose levels, increased prevalence of metabolic syndrome) in comparison to moderately fit and highly fit adolescents. In addition, adolescents who have low levels of cardiorespiratory fitness and positive energy balance are more likely to be overweight or obese compared with those with moderate or high levels of cardiorespiratory fitness. ${ }^{58}$

2. Children and adolescents who engage in moderate to vigorous-intensity physical activity have better cardiometabolic health (ie, systolic blood pressure, lipoprotein, glucose and insulin levels) independent of the amount of their sedentary time. ${ }^{59}$

3. There is evidence to suggest that children and adolescents having high levels of cardiorespiratory fitness have improved cardiovascular risk outcomes, including lower BMI, waist circumference and body fat, as well as a prevalence of metabolic dysregulation in later life. ${ }^{60}$

4. There is evidence to suggest that by replacing sedentary time and/or light-intensity physical activity with moderate to vigorous-intensity physical activity, children and adolescents may lower cardiometabolic risk factors, including waist circumference, systolic blood pressure, fasting high and lowdensity lipoprotein cholesterol, triglycerides, insulin and glucose. $^{61}$

5. There is evidence indicating that children and adolescents with overweight and obesity benefit from exercise interventions because these interventions improve their cardiometabolic and vascular health, cardiorespiratory fitness ${ }^{62}$ and motor skill development. ${ }^{63}$

\section{Theme 3: musculoskeletal fitness and health}

1. During childhood and adolescence, it is necessary to engage in weight-bearing physical activities, such as running and jumping, in order to attain peak bone mass and maintain healthy bone mineral accrual. ${ }^{64-67}$

2. A handful of exercise intervention studies $(n=11)$ indicates that moderate to high-impact activities (jumping, load bearing, resistance and ball game activity) performed at least 3 days a week can have a modest effect on bone mineral density. $^{68} 69$

3. Children and adolescents with better muscular fitness (eg, gained through exercises involving hand grip, standing, long jump and sit-ups) were shown to have better health outcomes (ie, lower levels of BMI and body fat, improvement in insulin resistance and lower levels of cardiovascular disease risk) in later life. ${ }^{68}$

\section{Theme 4: brain, cognition and academic achievement}

1. Being physically active and physically fit is positively associated with brain structure and function in children with high cardiorespiratory fitness levels (as shown in higher $\mathrm{VO}_{2} \mathrm{max}$ ). These children demonstrate larger brain volumes in the areas involved with memory and executive function and better memory task performance compared with children with low fitness levels. $^{70}$

2. There is a positive association between physical activity (both moderate to vigorous-intensity physical activity and vigorous-intensity physical activity) and physical fitness and academic performance in children and adolescents. ${ }^{71-74}$

3. There is evidence that physical activity interventions, including those of moderate to vigorous intensity, improve brain structure and function as well as cognitive and academic performance. ${ }^{75-79}$ However, a recent meta-analysis of highquality intervention studies shows strong evidence for the beneficial effects of physical activity on math performance but inconclusive evidence on the beneficial effects of physical activity interventions on cognition and overall academic performance in children. ${ }^{80}$

4. Engagement in moderate to vigorous-intensity physical activity both on weekdays and on weekends is associated with better academic performance among Chinese primary school students. ${ }^{81}$

\section{Theme 5: overweight and obesity}

1. The findings are inconsistent on the association between physical activity and overweight/obesity independent of calorie intake. Overall, evidence indicates no association or weak to modest association between physical activity and obesity, ${ }^{28-84}$ with no clear association reported in reviews of early prospective studies. ${ }^{83}$ There is a moderate negative association between walking, measured by pedometers, and decreased adiposity ${ }^{85}$ and between skill building and gamebased activities and body composition. ${ }^{86}$ The association with overweight/obesity tends to be stronger when moderate to vigorous-intensity physical activities are performed. ${ }^{2}$ Among physical activity interventions, the effects of physical activity independent of dietary changes on measures indicative of weight reduction (eg, BMI, total fat, abdominal fat) tend to be in the small range. ${ }^{2}$

2. There is insufficient evidence to draw firm conclusions on whether either school or community-based interventions employing low to vigorous intensities of physical activity are effective for preventing obesity.

3. Among children and adolescents who are either overweight or obese, evidence suggests that exercise interventions (without dietary change) may have desirable effects on body composition (body mass, BMI, central obesity and fat mass). Additionally, benefits of exercise interventions have been shown for cardiometabolic and vascular health as well as cardiorespiratory fitness. ${ }^{85}$

4. There is consensus that regular engagement in traditional sports, mainly football, may be as effective as general interventions based on physical activity for improving body composition and decreasing metabolic complications in children with obesity and may be appropriate, as a preventive intervention, for paediatric obesity treatment. ${ }^{86} 87$ 
5. There is evidence that elevated physical fitness in children and adolescents is associated with lower central obesity, ${ }^{88} 89$ an independent risk factor for cardiovascular-related diseases in adulthood. There is also some preliminary evidence that children (5-12 years old) following a year-round school calendar may benefit from experiencing less weight gain. ${ }^{90}$

\section{Theme 6: physical and mental health}

1. There is evidence that physical activity is associated with better mental health whereas sedentary behaviours (such as screen time) are associated with poorer mental health among children and adolescents. ${ }^{56} 91-93$ Domains of mental health include depression, stress, negative affect, psychological distress, self-image/self-esteem, satisfaction with life and happiness levels, and psychological well-being. Associations between physical activity and mental health outcomes, however, are generally weak in terms of effect sizes.

\section{Theme 7: individual perceptions and influences of significant} others

1. A host of perceived psychological factors impact the physical activity behaviours of children and adolescents. ${ }^{94}$ Among many salient factors, children and adolescents who have high levels of perceived competence, self-efficacy and access to physical activity/sports/recreational facilities are likely to participate in physical activity. ${ }^{95} 96$

2. Encouragement and modelling by peers, friends and parents are factors that motivate children and adolescents to participate in physical activity or achieve recommended levels of physical activity. ${ }^{97-104}$

3. There is some evidence to suggest that when parents reduce their own sedentary behaviours (including screen time), their children may decrease their screen time. ${ }^{105}$

4. Evidence from China indicates that there is a positive association between various forms of parental support, including parental encouragement, accompaniment, financial support, involvement, and role modelling, and high levels of physical activity participation among children and adolescents. ${ }^{106-108}$

\section{Theme 8: socioeconomic status, physical environment, built} environment and policy influences

1. There is consistent evidence of various environmental influences on the physical activity levels of children and adolescents. ${ }^{109-112}$ Commonly reported factors influencing physical activity levels include socioeconomic status (income and education), the physical environment (ambient air and water) and the built environment (neighbourhood design, parks and recreational facilities, green space, safety, access to physical activity facilities and street connectivity).

2. Evidence from China indicates that built environmental features in the community, such as availability and accessibility of open space, recreational facilities and walkable sidewalks, are likely to facilitate increased physical activity and active commuting, as well as reduced sedentary behaviours among Chinese children and adolescents. In contrast, features such as the lack of bike lanes and high residential density are likely to be associated with childhood overweight and obesity. ${ }^{109}$

3. Survey data indicate that school support for physical activity is important for promoting and facilitating moderate to vigorous-intensity physical activity among Chinese children and adolescents. In addition, availability of local community-based sports clubs and organisations and convenient access to physical activity facilities are also per- ceived as important resources for participating in moderate to vigorous-intensity physical activity among children and adolescents. ${ }^{113}$

4. There is some indication that a low level of public awareness and perceived impact exists among schoolchildren and adolescents, their parents and school staff regarding existing governmental policies and initiatives relating to physical activity. ${ }^{114}$

5. There is no clear evidence from China to suggest that socioeconomic status (eg, family socioeconomic status, parental education) is associated with levels of physical activity among Chinese children and adolescents. ${ }^{106}$

\section{Theme 9: interventions that promote physical activity in different settings}

1. There is some evidence that intervention strategies based at the school, home/family or community/neighbourhood level can increase physical activity in children and adolescents. ${ }^{115-120}$ School-based interventions that involve parents also have the potential to improve children's weight status, physical activity levels and sedentary behaviours. ${ }^{118}$ However, the effects of interventions using accelerometers to increase the overall physical activity of children and adolescents are generally reported to be negligible or small for moderate or vigorous-intensity physical activity interventions, regardless of age, BMI (overweight/obese) or implementation setting (home/family or school). ${ }^{119}$

2. In China, there is preliminary evidence that a policy-driven, multicomponent, school-based physical activity intervention may have the potential to increase physical activity and prevent the development of obesity in Chinese children. ${ }^{121}$ In addition, synthesised evidence on school-based interventions for preventing obesity among Chinese school-aged children suggests that comprehensive interventions involving physical activity and health education may be more effective than physical activity alone. ${ }^{122}$

\section{Theme 10: risk of injuries from participating in physical activities}

1. There is some risk of injuries or overuse injuries among children and adolescents who participate in physical activities and sports, ${ }^{123}$ as well as organised and unorganised leisuretime physical activity ${ }^{12}$ with the evidence suggesting high numbers of injuries when participating in sports-related activities, ${ }^{124}$ unorganised activities ${ }^{125}$ and high-risk sports (eg, ice hockey). ${ }^{126}$ In general, as the level of physical activity increases, the likelihood of injury increases. ${ }^{2}$

2. In China, limited data indicate that injury risk is related to physical activity, with a high prevalence of activity-related injuries reported by boys and junior high students. ${ }^{127} 128$ In addition, a high prevalence of injuries is also reported by those who participate in team sports, have lower safety awareness, exercise in slippery conditions, overextend their play, ${ }^{127}$ have excessive workout loads and do not warm up sufficiently. ${ }^{128}$

\section{CAVEATS}

Panel experts are cognisant of the following caveats inherent in this consensus:

1. Due to the limited number of high-quality Chinese-based studies and the paucity of research in certain areas of health, evidence for this consensus was drawn primarily from international studies that were predominantly based on Caucasian populations. 
2. Consensus statements are based on the panel's best judgement regarding the current state of the art of research rather than on a quantitative synthesis (eg, a meta-analysis) of empirical data. Future updates of the consensus should consider the use of the Grading of Recommendations Assessment, Development and Evaluation process model as a more stringent approach in evaluating studies, assessing the quality of the evidence and making guidelines/recommendations for systematic reviews and guidelines. Such an approach has become common in recent years in the field of physical activity. ${ }^{39} 129130$

3. The consensus focuses primarily on Chinese school-aged children and adolescents without disabling conditions; it does not therefore offer any consensus related to physical activity for children and adolescents with physical disabilities.

4. This is a consensus on physical activity. However, the panel recognises the importance of children and adolescents having a healthy diet, balanced dietary behaviours and physically active lifestyle for healthy growth, lifelong well-being and obesity prevention.

5. Limitations in the available evidence summarised and included in this consensus may restrict the ability to draw absolute conclusions.

\section{FUTURE UPDATES}

The panel agrees that the consensus should be updated every 5 years from the publication of this statement.

\section{PROMOTING PHYSICAL ACTIVITY: CHALLENGES AND BARRIERS}

The Healthy China 2030 Action Plan specifically emphasises that schoolchildren and adolescents participate in no less than $60 \mathrm{~min}$ of daily in-school physical activity. To ensure that more than $25 \%$ of the nation's school population achieves an 'excellent' rating in fitness, this physical activity should include moderate-intensity activities that occur at least three times per week. ${ }^{35}$ However, promoting an active and healthy lifestyle among Chinese schoolaged children and adolescents remains a significant challenge in practice. ${ }^{12}{ }^{13}$ In this regard, the panel recognises the following challenges and practical barriers in promoting physical activity for school-aged children and adolescents:

- Despite a wealth of evidence about the health benefits of physical activity for children and adolescents, practice and promotion of physical activity for Chinese children and youth has not been given a high public health priority at the school, community and policy level.

- There is a significant lack of school and community-based physical activity interventions or programmes that can guide and aid the development of national physical activity guidelines for Chinese children and adolescents.

- Promoting physical activity requires policies. Currently, there is a lack of school-based physical activity policies and initiatives established on a local, provincial or national scale that can effectively promote, impact and sustain school-level physical activities for children and adolescents inside and outside school settings.

- Given the major emphasis in China on academic excellence over physical education and recreational physical activity, there is a significant cultural challenge in changing attitudes and expectations of parents and schools with regard to meeting recommended physical activity or physical fitness levels.
- There is a lack of partnerships in which a wide variety of organisations (eg, schools, parents, public education, private organisations, community groups) can collaborate to promote physical activity for children and adolescents.

- There is a lack of information on potential barriers to promoting and implementing physical activity policies in school and/or community settings.

\section{RESEARCH NEEDS AND GAPS}

Given the significant limitations on the number of research studies on physical activity among Chinese children and adolescents, the panel recommends future research in the following areas:

- Continued ongoing periodic surveillance on physical activity, cardiorespiratory and musculoskeletal fitness levels and other behavioural risk factors (ie, sedentary time, BMI) among Chinese children and adolescents at the regional and national levels. Such surveillance would offer insights into the prevalence of compliance with physical activity recommendations, including meeting the WHO physical activity guidelines ${ }^{40}$ and the Canadian 24-Hour Movement Guidelines, of which the latter calls for a minimum number hours of sleep per night, a reduction in sedentary behaviours and an increase in light-intensity and moderate to vigorousintensity physical activities. ${ }^{46}$

- Large-scale population cohort studies that track and examine longitudinal changes in sedentary behaviours, physical activity levels, cardiorespiratory and musculoskeletal fitness, BMI and other cardiometabolic risk factors associated with physical activity levels over time, including those for diabetes, hypertension and bone health. ${ }^{131-138}$

- Cross-sectional and longitudinal prospective cohort studies that focus on examining culturally specific determinants of and health risks associated with sedentary behaviours and low levels of physical activity among school-aged children and adolescents.

- Prospective cohort studies that focus on understanding associations between children and adolescents' lifestyle behaviours (physical activities, sedentary behaviours and sleep) and various levels and improvements in body composition, cardiorespiratory and musculoskeletal fitness, cardiovascular and metabolic health, academic achievement and cognition, and mental health and quality of life.

- Cross-sectional and prospective cohort studies that aim to identify culturally relevant forms of physical activity (eg, traditional Chinese martial arts, table tennis, badminton) and expand physical activity opportunities in various settings, including out-of-school, neighbourhood and community public facility settings. Findings from these studies can be used to encourage and maximise yearlong physical activity and sports participation among children and adolescents.

- Randomised trials aimed at evaluating and establishing the effectiveness of school-based physical activity interventions, including activities or bouts of activities implemented during school break time and after-school hours, as well as before and after major school examinations.

- Research that informs policies and interventions regarding differences in patterns and types of physical activities and sports as they relate to children and adolescent boys and girls and those living in rural versus urban/suburban areas.

- Development and efficacy evaluation of culturally and contextually relevant forms of physical activity (and dietary) interventions aimed at preventing and reducing overweight 
and obesity among children and adolescents. This effort should include both school-based and community-based interventions that consider the type/form (aerobic, muscle strengthening) and dose (frequency, duration, intensity) of activity as well as the dietary context.

- Research related to the deepening of the impact of Chinese school-based physical activity policies and initiatives on participation in recommended levels of physical activity both inside and outside of school settings. Relatedly, research is needed to understand the impact of school academic policies and parental pressure on children's academic excellence on the level of children and adolescents' physical activity both inside and outside of school settings.

- Intervention research that focuses on the effects of physical activity interventions in ameliorating psychosocial stress and improving mental health among children and adolescents.

- Given the traditional cultural values and expectations related to academic achievement in China, there is a need to develop home-based physical activity programmes that allow children to reallocate their sedentary time spent on completing homework to light to vigorous-intensity physical activities in home settings.

- Development of physical activity interventions aimed at increasing physical activity, particularly in settings outside the school environment. This may include, for example, studies that examine the effectiveness of home or familybased interventions (involving parents and grandparents), as well as community-based interventions and strategies implemented in school or neighbourhood settings.

- Research on capacity assessments and capacity building for schools, neighbourhoods and organisations that can adopt, implement and promote the Healthy China 2030 physical activity initiative for school-aged children and adolescents.

- Conduct natural studies to evaluate the impact of major regional or global public health crises, such as the COVID-19 pandemic, on physical activity opportunities and behaviours. Reduced regular physical activity and increased sedentary behaviours can occur through the closure of public facilities, disrupted transportation systems and the imposition of stay-at-home and physical distancing restrictions. ${ }^{139}$ Therefore, there is a clear public health imperative to be proactive in developing and evaluating strategies to effectively promote safe physical activity engagement for children and adolescents during and in the aftermath of such crises. ${ }^{140} 141$

\section{EVIDENCE-BASED MESSAGES FOR TEACHERS, EDUCATION EXPERTS, PARENTS AND POLICYMAKERS ON PHYSICAL ACTIVITY AMONG SCHOOL-AGED CHILDREN AND ADOLESCENTS}

- Structured physical activity and/or leisure-time sports and recreational physical activities that are of moderate to vigorous intensity and reduced time spent in sedentary behaviours provide multiple health benefits for child and adolescent populations. Such benefits include, but are not limited to, cardiorespiratory, muscular and cardiometabolic fitness; cognitive functioning; and physical and mental health.

- It is important to accumulate $60 \mathrm{~min}$ or more of daily moderate to vigorous-intensity physical activity that involves components of aerobic, strengthening and bone-building (weight-bearing) exercises, sports and/or recreational activities.
- Recreational and non-school screen time in which children and adolescents are physically inactive should be limited to no more than 2 hours per day.

- Physical activity should be encouraged during the schooldays as it helps control childhood weight and reduces the risk of developing negative health conditions (eg, heart disease, type 2 diabetes, overweight and obesity).

- Providing social support and creating conducive playable environments encourages physical activity of various kinds.

\section{JOINING THE GLOBAL EFFORT TO REDUCE PHYSICAL INACTIVITY}

Physical inactivity and low levels of physical activity are a global public health problem associated with an array of negative health outcomes for school-aged children and adolescents. China has not been immune to this global concern as evidenced by inadequate levels of physical activity and energy imbalance among its approximately 170 million children and adolescents. This problem, coupled with obesogenic environments, lack of safe and accessible exercise facilities and socially imposed pressures to excel scholastically, presents a significant, culturally specific challenge to the realisation of the action plans established in the Healthy China 2030 blueprint $^{35}$ and other global efforts. ${ }^{36-38}$

The WHO and numerous countries globally have issued action plans to reduce physical inactivity and promote increased levels of physical activity. The newly developed WHO Global Action Plan on Physical Activity 2018-2030 identifies four strategic objectives to reduce time spent in inactive behaviours by $2030 .{ }^{36}$ National physical activity action plans are a 'call to action' for proactive initiatives to increase physical activity using strategies and locations that reflect the social, cultural, economic and political contexts of a country. ${ }^{142-146}$ Therefore, developing and prioritising physical activity promotion policies, strategies and campaigns to increase awareness of existing international and national guidelines and to scale up levels of physical activity among the youth population in China is urgently needed. These concerted efforts require a public health approach ${ }^{13}$ and strategies that are based on the best available scientific evidence. ${ }^{37}$

In this regard, this consensus, which is the first of its kind in China, aligns with the Healthy China 2030 blueprint, ${ }^{35}$ WHO Global Action Plan on Physical Activity 2018-2030 $0^{36}$ and the soon-to-be-released WHO Guidelines on Physical Activity and Sedentary Behaviour. ${ }^{38}$ Taken together, these resources, which are all aimed at reducing sedentary behaviour and increasing physical activity among school-aged children and adolescents, will become a driver for developing the school, clinical and community-based interventions that are urgently needed to reverse the trends in physical inactivity and the rapidly growing obesity crisis among Chinese youths. Additionally, the lessons learnt from the implementation of recommendations in the consensus statement will provide data for comparison to other low to moderate-income and high-income countries and, additionally, expand national and global evidence on effective strategies and interventions that promote physical activity and reduce the obesity pandemic.

\section{CONCLUSIONS}

There is strong scientific evidence that children and adolescents benefit substantially in multiple health and fitness domains from engaging in $60 \mathrm{~min}$ or more of moderate to vigorous daily physical activity, and these benefits continue throughout their lives. Promoting physical activity among Chinese children and adolescents is both urgent and important because this population 
continues to engage in activities that contribute to physical inactivity and place them at increased risk for overweight and obesity and related conditions that are detrimental to health. These conditions are most attributable to the imbalance between sufficient physical activity and overprioritising academic achievement, which results in an overload of schoolwork, as well as a high prevalence of sedentary behaviours, predominantly characterised by time spent in screen-based activities. In order to encourage a physically active lifestyle among children and adolescents, a comprehensive, evidence-based strategic plan is urgently warranted. This consensus serves as a scientific foundation for developing such a plan, and the successful promotion of physical activity among Chinese children and youth would also serve as a positive example for public health and health promotion throughout the world.

\section{Author affiliations}

${ }^{1}$ Shanghai University of Sport, Shanghai, China

${ }^{2}$ Department of Physical, Health and Arts Education, Ministry of Education of People's Republic of China, Beijing, China

${ }^{3}$ Nanjing Medical University, Nanjing, Jiangsu, China

${ }^{4}$ Shanghai Municipal People's Government, Shanghai, China

${ }^{5}$ School of Medicine, Nanjing University, Nanjing, Jiangsu, China

${ }^{6}$ Shanghai Municipal Education Commission, Shanghai, China

${ }^{7}$ Department of Developmental and Behavioral Pediatrics, Shanghai Children's

Medical Center, Shanghai Jiao Tong University School of Medicine, Shanghai, China

${ }^{8}$ Shenzhen Key Laboratory of Affective and Social Neuroscience, Shenzhen University, Shenzhen, Guangdong, China

${ }^{9}$ Institute of Sports Medicine, General Administration of Sport of China, Beijing, China

${ }^{10}$ Tianjin Key Laboratory of Exercise Physiology and Sports Medicine, Tianjin University of Sport, Tianjin, China

${ }^{11}$ China Institute of Sport Science, Beijing, China

${ }^{12}$ School of Aerospace Medicine, Fourth Military Medical University, Xi'an, Shaanxi, China

${ }^{13}$ Department of Rehabilitation Medicine, The Sixth Affiliated Hospital of Sun Yat-sen University, Guangzhou, China

${ }^{14}$ Shanghai Municipal Center for Disease Control and Prevention, Shanghai, China

${ }^{15}$ Department of Sports Science and Clinical Biomechanics, University of Southern Denmark, Faculty of Health Sciences, Odense, Denmark

${ }^{16}$ School of Physical Education and Sports Training, Shanghai University of Sport, Shanghai, China

${ }^{17}$ College of Health Solutions, Arizona State University, Phoenix, Arizona, USA

${ }^{18}$ Department of Exercise and Health Science, Willamette University, Salem, Oregon, USA

${ }^{19}$ Oregon Research Institute, Eugene, Oregon, USA

\section{Twitter George P Nassis @gnassis}

Acknowledgements The authors thank Yahua Zi and Yiao Tong for their assistance in compiling and verifying the data provided in the article.

Contributors PC, LM, LY and FL were responsible for the overall content as guarantors of the consensus statement, manuscript planning, literature search strategy and writing the first draft of the manuscript. PC, FL, BA, YL and GPN were responsible for the consensus statement concept, data interpretation and manuscript editing. All authors on this paper were involved in data interpretation, and writing, editing and critical revision of multiple versions of the manuscript.

Funding The work presented in this article was supported by the Key Project of the National Social Science Fund of China (19ZDA352).

Competing interests None declared.

Patient consent for publication Not required.

Provenance and peer review Not commissioned; externally peer reviewed.

Data availability statement All data relevant to the study are included in the article or uploaded as supplementary information.

Open access This is an open access article distributed in accordance with the Creative Commons Attribution Non Commercial (CC BY-NC 4.0) license, which permits others to distribute, remix, adapt, build upon this work non-commercially, and license their derivative works on different terms, provided the original work is properly cited, appropriate credit is given, any changes made indicated, and the use is non-commercial. See: http://creativecommons.org/licenses/by-nc/4.0/.

\section{ORCID iDs}

Peijie Chen http://orcid.org/0000-0003-2075-3133

George P Nassis http://orcid.org/0000-0003-2953-3911

Peter Krustrup http://orcid.org/0000-0002-1461-9838

Fuzhong Li http://orcid.org/0000-0001-6644-4702

\section{REFERENCES}

1 Poitras VJ, Gray CE, Borghese MM, et al. Systematic review of the relationships between objectively measured physical activity and health indicators in school-aged children and youth. App/ Physiol Nutr Metab 2016:41:S197-239.

2 Janssen I, LeBlanc AG. Systematic review of the health benefits of physical activity and fitness in school-aged children and youth. Int J Behav Nutr Phys Act 2010;7:40.

3 Physical Activity Guidelines Advisory Committee. Physical activity guidelines Advisory Committee scientific report. Washington, DC: U.S. Department of Health and Human Services, 2018. https://health.gov/our-work/physical-activity/current-guidelines/ scientific-report

4 Granger E, Di Nardo F, Harrison A, et al. A systematic review of the relationship of physical activity and health status in adolescents. Eur J Public Health 2017; 27:100-6

5 Kemper HC, Monyeki KD. The Amsterdam growth and health longitudinal study: how important is physical activity in youth for later health? (ELS 33). Cardiovasc J Afr 2019:30:138-41.

6 Hallal PC, Andersen LB, Bull FC, et al. Global physical activity levels: surveillance progress, pitfalls, and prospects. The Lancet 2012;380:247-57.

7 WHO Regional Office for Europe. Adolescent obesity and related behaviours: trends and inequalities in the WHO European Region, 2002-2014. Copenhagen, 2017. Available: http://www.euro.who.int/_data/assets/pdf_file/0019/339211/WHO_ ObesityReport_2017 v3.pdf [Accessed 20 Jan 2020].

8 Vancampfort D, Van Damme T, Firth J, et al. Correlates of physical activity among 142,118 adolescents aged 12-15 years from 48 low- and middle-income countries. Prev Med 2019;127:105819.

9 Tremblay MS, Barnes JD, González SA, et al. Global matrix 2.0: report card grades on the physical activity of children and youth comparing 38 countries. J Phys Act Health 2016:13:\$343-66.

10 Aubert S, Barnes JD, Abdeta C, et al. Global matrix 3.0 physical activity report card grades for children and youth: results and analysis from 49 countries. J Phys Act Health 2018:15:S251-73.

11 Guthold R, Stevens GA, Riley LM, et al. Global trends in insufficient physical activity among adolescents: a pooled analysis of 298 population-based surveys with 1.6 million participants. Lancet Child Adolesc Health 2020;4:23-35.

12 Chen P. Physical activity, physical fitness, and body mass index in the Chinese child and adolescent populations: an update from the 2016 physical activity and fitness in China-The youth study. J Sport Health Sci 2017:6:381-3.

13 Li F, Mao L, Chen P. Physical activity and prevention of chronic disease in Chinese youth: a public health approach. J Sport Health Sci 2019:8:512-5.

14 Zhang $X$, Song $Y$, Yang TB, et al. Analysis of current situation of physical activity and influencing factors in Chinese primary and middle school students in 2010. Zhonghua Yu Fang Yi Xue Za Zhi 2012;46:781-8.

15 Ao D, Wu F, Yun C-F, et al. Trends in physical fitness among 12-year-old children in urban and rural areas during the social transformation period in China. J AdolesC Health 2019:64:250-7.

16 Song C, Gong W, Ding C, et al. Physical activity and sedentary behavior among Chinese children aged 6-17 years: a cross-sectional analysis of 2010-2012 China National Nutrition and health survey. BMC Public Health 2019;19:936.

17 Dong Y, Lau PWC, Dong B, et al. Trends in physical fitness, growth, and nutritional status of Chinese children and adolescents: a retrospective analysis of 1.5 million students from six successive national surveys between 1985 and 2014. Lancet Child Adolesc Health 2019;3:871-80.

18 Zhu Z, Yang Y, Kong Z, et al. Prevalence of physical fitness in Chinese school-aged children: findings from the 2016 physical activity and fitness in China-The youth study. J Sport Health Sci 2017;6:395-403.

19 Fan X, Cao Z-B. Physical activity among Chinese school-aged children: national prevalence estimates from the 2016 physical activity and fitness in China-The youth study. J Sport Health Sci 2017;6:388-94.

20 Zhu Z, Tang Y, Zhuang J, et al. Physical activity, screen viewing time, and overweight/obesity among Chinese children and adolescents: an update from the 2017 physical activity and fitness in China-the youth study. BMC Public Health 2019;19:197.

21 Yan Y, Liu J, Zhao X, et al. Cardiovascular health in urban Chinese children and adolescents. Ann Med 2019:51:88-96.

22 Cai Y, Zhu X, Wu X. Overweight, obesity, and screen-time viewing among Chinese school-aged children: national prevalence estimates from the 2016 physical activity and fitness in China-The youth study. J Sport Health Sci 2017;6:404-9. 
23 Dong Y, Jan C, Ma Y, et al. Economic development and the nutritional status of Chinese school-aged children and adolescents from 1995 to 2014: an analysis of five successive national surveys. Lancet Diabetes Endocrinol 2019;7:288-99.

24 Ma G. Report on children obesity. Beijing: People's Medical Publishing House Co, 2017.

25 Kelly AS, Barlow SE, Rao G, et al. Severe obesity in children and adolescents: identification, associated health risks, and treatment approaches: a scientific statement from the American heart association. Circulation 2013;128:1689-712.

26 Sutaria S, Devakumar D, Yasuda SS, et al. Is obesity associated with depression in children? systematic review and meta-analysis. Arch Dis Child 2019;104:64-74.

27 Piernas C, Wang D, Du S, et al. Obesity, non-communicable disease (Ncd) risk factors and dietary factors among Chinese school-aged children. Asia Pac J Clin Nutr 2016;25:826-40.

28 Yan S, Li J, Li S, et al. The expanding burden of cardiometabolic risk in China: the China health and nutrition survey. Obes Rev 2012;13:810-21.

29 Liang Y-J, Xi B, Hu Y-H, et al. Trends in blood pressure and hypertension among Chinese children and adolescents: China health and nutrition surveys 1991-2004. Blood Press 2011;20:45-53.

30 Tang $X$, Tang S, Ren Z, et al. Prevalence of depressive symptoms among adolescents in secondary school in mainland China: a systematic review and meta-analysis. J Affect Disord 2019;245:498-507.

31 Rao W-W, Xu D-D, Cao X-L, et al. Prevalence of depressive symptoms in children and adolescents in China: a meta-analysis of observational studies. Psychiatry Res 2019;272:790-6

32 DD X, Rao WW, Cao XL, et al. Prevalence of major depressive disorder in children and adolescents in China: a systematic review and meta-analysis. J Affec Disord 2018;241:592-8.

33 Zhao X, Selman RL, Haste H. Academic stress in Chinese schools and a proposed preventive intervention program. Cogent Education 2015;2:1000477.

34 Sun J, Dunne MP, Hou X-yu, et al. Educational stress among Chinese adolescents: individual, family, school and peer influences. Educational Review 2013;65:284-302.

35 The State Council. The People's Republic of China. Outline of the "Healthy China 2030" Plan, 2016. Available: http://www.gov.cn/zhengce/2016-10/25/content_ 5124174.htm [Accessed 4 May 2020].

36 World Health Organisation. Global Action Plan on Physical Activity 2018-2030 More active people for a healthier world, 2018. Available: https://apps.who.int/iris/ bitstream/handle/10665/272722/9789241514187-eng.pdf [Accessed 1 May 2020]

37 World Health Organisation. Interventions on diet and physical activity: what works. Available: https://apps.who.int/iris/bitstream/handle/10665/44140/ 9789241598248_eng.pdf; jsessionid=E4193E7EFD5C1AA4485EF359A38621AE? sequence $=1$ [Accessed 1 May 2020].

38 World Health Organisation. Public consultation on the draft WHO Guidelines on physical activity and sedentary behaviour for children and adolescents, adults and older adults, 2020. Available: https://www.who.int/news-room/articles-detail/ public-consultation-on-the-draft-who-guidelines-on-physical-activity-and-sedentarybehaviour-for-children-and-adolescents-adults-and-older-adults-2020 [Accessed 1 May 2020].

39 Parrish A-M, Tremblay MS, Carson S, et al. Comparing and assessing physical activity guidelines for children and adolescents: a systematic literature review and analysis. Int J Behav Nutr Phys Act 2020;17:16.

40 World Health Organization. Physical activity and young people - Recommended levels of physical activity for children aged 5 - 17 years. Available: https://www. who.int/dietphysicalactivity/factsheet_young_people/en/ [Accessed February 29, 2020].

41 Centers for Disease Control and Prevention, U.S. Department of health and human services. physical activity guidelines for children and adolescents, 2018. Available: https://www.cdc.gov/healthyschools/physicalactivity/guidelines.htm [Accessed 2 March 2020]

42 Canadian Society for Exercise Physiology. Canadian 24-hour movement guidelines for children and youth (ages 5-17 years): an integration of physical activity, sedentary behavior and sleep. Available: https://csepguidelines.ca/children-andyouth-5-17 [Accessed 2 March 2020].

43 National Health Service. United Kingdom physical activity guidelines for children and young people, 2019. Available: https://www.nhs.uk/live-well/exercise/physicalactivity-guidelines-children-and-young-people [Accessed 1 Feb 2020]

44 Australian Government, Department of Health. Australia's Physical Activity and Sedentary Behavior Guidelines. Available: https://www1.health.gov.au/internet/main/ publishing.nsf/Content/health-pubhlth-strateg-phys-act-guidelines/\$File/FS-Children5-12-Years.PDF [Accessed 1 Sep 2019].

45 World Health Organization. What is moderate-intensity and vigorous-intensity physical activity? Available: https://www.who.int/dietphysicalactivity/physical_ activity_intensity/en/ [Accessed 1 Jul 2019].

46 Tremblay MS, Carson V, Chaput J-P, et al. Canadian 24-hour movement guidelines for children and youth: an integration of physical activity, sedentary behaviour, and sleep. Appl Physiol Nutr Metab 2016;41:\$311-27.

47 Chinese Task force guidelines on physical activity among Chinese children and adolescents. Chinese children and adolescents physical activity guidelines. Chin J Evid Based Pediatr 2017;12:401-9.
48 Caspersen CJ. Physical activity epidemiology: concepts, methods, and applications to exercise science. Exerc Sport Sci Rev 1989:17:423-73.

49 Butte NF, Watson KB, Ridley K, et al. A youth compendium of physical activities: activity codes and metabolic intensities. Med Sci Sports Exerc 2018:50:246-56.

50 Hibbing PR, Bassett DR, Coe DP, et al. Youth metabolic equivalents differ depending on operational definitions. Medicine \& Science in Sports \& Exercise 2020:1

51 World Health Organization. Who Handbook for Guideline development, 2nd ed. 2014, 2014. Available: https://apps.who.int/iris/handle/10665/145714 [Accessed 1 May 2020].

52 Centers for Disease Control and Prevention. Physical activity facts. Available: https:// www.cdc.gov/healthyschools/physicalactivity/facts.htm [Accessed 1 Sep 2019].

53 Bangsbo J, Krustrup P, Duda J, et al. The Copenhagen consensus conference 2016: children, youth, and physical activity in schools and during leisure time. $\mathrm{Br} J$ Sports Med 2016:50:1177-8.

54 Telama R, Yang X, Viikari J, et al. Physical activity from childhood to adulthood: a 21-year tracking study. Am J Prev Med 2005;28:267-73.

55 Telama R, Yang X, Leskinen E, et al. Tracking of physical activity from early childhood through youth into adulthood. Medicine \& Science in Sports \& Exercise 2014:46:955-62.

56 Carson V, Hunter S, Kuzik N, et al. Systematic review of sedentary behaviour and health indicators in school-aged children and youth: an update. App/ Physiol Nutr Metab 2016;41:\$240-65.

57 Tam CS, Ravussin E. Energy balance: an overview with emphasis on children. Pediat Blood Cancer 2012;58:154-8.

58 Carnethon MR, Gulati M, Greenland P. Prevalence and cardiovascular disease correlates of low cardiorespiratory fitness in adolescents and adults. JAMA 2005:294:2981-8.

59 Ekelund U, Luan J, Sherar LB, et al. International children's Accelerometry database (ICAD) Collaborators. moderate to vigorous physical activity and sedentary time and cardiometabolic risk factors in children and adolescents. JAMA 2012;307:704-12.

60 Mintjens S, Menting MD, Daams JG, et al. Cardiorespiratory fitness in childhood and adolescence affects future cardiovascular risk factors: a systematic review of longitudinal studies. Sports Med 2018;48:2577-605.

61 Hansen BH, Anderssen SA, Andersen LB, et al. Cross-Sectional Associations of Reallocating Time Between Sedentary and Active Behaviours on Cardiometabolic Risk Factors in Young People: An International Children's Accelerometry Database (ICAD) Analysis. Sports Med 2018;48:2401-12

62 García-Hermoso A, Ramírez-Vélez R, Saavedra JM. Exercise, health outcomes, and pædiatric obesity: a systematic review of meta-analyses. Journal of Science and Medicine in Sport 2019;22:76-84

63 Han A, Fu A, Cobley S, et al. Effectiveness of exercise intervention on improving fundamental movement skills and motor coordination in overweight/obese children and adolescents: a systematic review. Journal of Science and Medicine in Sport 2018;21:89-102

64 Gunter KB, Almstedt HC, Janz KF. Physical activity in childhood may be the key to optimizing lifespan skeletal health. Exerc Sport Sci Rev 2012;40:13-21.

65 Golden NH, Abrams SA. Committee on nutrition. optimizing bone health in children and adolescents. Pediatrics 2014;134:e1229.

66 MacKelvie KJ, Khan KM, McKay HA. Is there a critical period for bone response to weight-bearing exercise in children and adolescents? A systematic review * commentary. Br J Sports Med 2002:36:250-7.

67 Ondrak KS, Morgan DW. Physical activity, calcium intake and bone health in children and adolescents. Sports Medicine 2007:37:587-600.

68 García-Hermoso A, Ramírez-Campillo R, Izquierdo M. Is muscular fitness associated with future health benefits in children and adolescents? A systematic review and meta-analysis of longitudinal studies. Sports Med 2019:49:1079-94.

69 Larsen MN, Nielsen CM, Helge EW, et al. Positive effects on bone mineralisation and muscular fitness after 10 months of intense school-based physical training for children aged 8-10 years: the FIT FIRST randomised controlled trial. Br J Sports Med 2018:52:254-60.

70 Chaddock L, Erickson KI, Prakash RS, et al. A neuroimaging investigation of the association between aerobic fitness, hippocampal volume, and memory performance in preadolescent children. Brain Res 2010;1358:172-83.

71 Lima RA, Larsen LR, Bugge A, et al. Physical fitness is longitudinally associated with academic performance during childhood and adolescence, and waist circumference mediated the relationship. Pediatr Exerc Sci 2018:30:317-25.

72 Michael SL, Merlo CL, Basch CE, et al. Critical connections: health and academics. J School Health 2015:85:740-58.

73 Howie EK, Pate RR. Physical activity and academic achievement in children: a historical perspective. Journal of Sport and Health Science 2012:1:160-9.

74 Donnelly JE, Hillman CH, Castelli D, et al. Physical activity, fitness, cognitive function, and academic achievement in children. Medicine \& Science in Sports \& Exercise 2016:48:1197-222.

75 Castelli DM, Centeio EE, Hwang J, et al. Vii. The history of physical activity and academic performance research: Informing the future. Monogr Soc Res Child Dev 2014;79:119-48. 
76 Erickson K, Hillman C, Stillman C, et al. Physical activity, cognition, and brain outcomes: a review of the 2018 physical activity guidelines. Med Sci Sports Exerc 2019;51:1242-51.

77 Álvarez-Bueno C, Pesce C, Cavero-Redondo I, et al. Academic achievement and physical activity: a meta-analysis. Pediatrics 2017;140:e20171498.

78 Álvarez-Bueno C, Pesce C, Cavero-Redondo I, et al. The Effect of Physical Activity Interventions on Children's Cognition and Metacognition: A Systematic Review and Meta-Analysis. J Am Acad Child Adolesc Psychiatry 2017;56:729-38.

79 Lind RR, Beck MM, Wikman J, et al. Acute high-intensity football games can improve children's inhibitory control and neurophysiological measures of attention. Scand J Med Sci Sports 2019;29:1546-62.

80 Singh AS, Saliasi E, van den Berg V, et al. Effects of physical activity interventions on cognitive and academic performance in children and adolescents: a novel combination of a systematic review and recommendations from an expert panel. $\mathrm{Br} J$ Sports Med 2019;53:640-7.

81 Zhang Y, Niu L, Zhang D, et al. Social-emotional functioning explains the effects of physical activity on academic performance among Chinese primary school students: a mediation analysis. J Pediatr 2019;208:74-80.

82 Jiménez-Pavón D, Kelly J, Reilly JJ. Associations between objectively measured habitual physical activity and adiposity in children and adolescents: systematic review. Obesity 2010;5:3-18.

83 Wilks DC, Besson $\mathrm{H}$, Lindroos AK, et al. Objectively measured physical activity and obesity prevention in children, adolescents and adults: a systematic review of prospective studies. Obesity Rev 2011;12:e119-29.

84 Miguel-Berges ML, Reilly JJ, Moreno Aznar LA, et al. Associations between Pedometer-Determined physical activity and adiposity in children and adolescents: systematic review. Clin J Sport Med 2018;28:64-75.

85 García-Hermoso A, Ramírez-Vélez R, Saavedra JM. Exercise, health outcomes, and pædiatric obesity: a systematic review of meta-analyses. I Sci Med Sport 2019:22:76-84.

86 Ørntoft C, Fuller C, Larsen MN, et al. 'FIFA 11 for Health' in Europe. II: effect on health markers and physical fitness in Danish schoolchildren aged 10-12 years. Br J Sports Med 2016:50:1394-9.

87 Ring-Dimitriou S, Krustrup P, Coelho-E-Silva MJ, et al. Could sport be part of pediatric obesity prevention and treatment? Expert conclusions from the $28^{\text {th }}$ European Childhood Obesity Group Congress. J Sport Health Sci 2019;8:350-2.

88 Nassis GP, Psarra G, Sidossis LS. Central and total adiposity are lower in overweight and obese children with high cardiorespiratory fitness. Eur J Clin Nutr 2005:59:137-41.

89 Lee SJ, Arslanian SA. Cardiorespiratory fitness and abdominal adiposity in youth. Eur J Clin Nutr 2007:61:561-5.

90 Weaver RG, Hunt E, Rafferty A, et al. The potential of a year-round school calendar for maintaining children's weight status and fitness: preliminary outcomes from a natural experiment. J Sport Health Sci 2020;9:18-27.

91 Biddle SJH, Asare M. Physical activity and mental health in children and adolescents: a review of reviews. Br J Sports Med 2011:45:886-95.

92 Asare M. Sedentary behaviour and mental health in children and adolescents: a meta-analysis. J Child Adolesc Behav 2015;03:259.

93 Rodriguez-Ayllon M, Cadenas-Sánchez C, Estévez-López F, et al. Role of physical activity and sedentary behavior in the mental health of preschoolers, children and adolescents: a systematic review and meta-analysis. Sports Med 2019:49:1383-410.

94 Sallis JF, Prochaska JJ, Taylor WC. A review of correlates of physical activity of children and adolescents. Medicine \& Science in Sports \& Exercise 2000;32:963-75.

95 Sterdt E, Liersch S, Walter U. Correlates of physical activity of children and adolescents: a systematic review of reviews. Health Edu J 2013;73.

96 Biddle SJH, Atkin AJ, Cavill N, et al. Correlates of physical activity in youth: a review of quantitative systematic reviews. Int Rev Sport Exerc Psychol 2011;4:25-49.

97 Laird Y, Fawkner S, Kelly P, et al. The role of social support on physical activity behavior in adolescent girls: a systematic review and meta-analysis. Int J Behav Nutr Phys Act 2016:21:79.

98 Yao CA, Rhodes RE. Parental correlates in child and adolescent physical activity: a meta-analysis. Int J Behav Nutr Phys Act 2015;12.

99 Mendonça G, Cheng LA, Mélo EN, et al. Physical activity and social support in adolescents: a systematic review. Health Educ Res 2014;29:822-39.

100 Beets MW, Cardinal BJ, Alderman BL. Parental social support and the physical activity-related behaviors of youth: a review. Health Educ Behav 2010;37:621-44

101 Edwardson CL, Gorely T. Parental influences on different types and intensities of physical activity in youth: a systematic review. Psychol Sport Exerc 2010;11:522-35

102 Fitzgerald A, Fitzgerald N, Aherne C. Do peers matter? A review of peer and/ or friends' influence on physical activity among American adolescents. J Adolesc 2012:35:941-58

103 Gustafson SL, Rhodes RE. Parental correlates of physical activity in children and early adolescents. Sports Medicine 2006:36:79-97.

104 Maturo CC, Cunningham SA. Influence of Friends on Children's Physical Activity: A Review. Am J Public Health 2013;103:e23-38.

$105 \mathrm{Xu} \mathrm{H}$, Wen LM, Rissel C. Associations of parental influences with physical activity and screen time among young children: a systematic review. J Obes 2015;2015:1-23.
106 Lu C, Stolk RP, Sauer PJ, et al. Factors of physical activity among Chinese children and adolescents: a systematic review. Int J Behav Nutr Phys Act 2017;14:36.

107 Liu Y, Zhang Y, Chen S, et al. Associations between parental support for physical activity and moderate-to-vigorous physical activity among Chinese school children: a cross-sectional study. J Sport Health Sci 2017;6:410-5

108 Wang X, Liu Q-M, Ren Y-J, et al. Family influences on physical activity and sedentary behaviours in Chinese junior high school students: a cross-sectional study. BMC Public Health 2015;15:287.

109 An R, Shen J, Yang Q, et al. Impact of built environment on physical activity and obesity among children and adolescents in China: a narrative systematic review. J Sport Health Sci 2019;8:153-69.

110 Davison K, Lawson CT. Do attributes in the physical environment influence children's physical activity? A review of the literature. Int J Behav Nutr Phys Act 2006;3:19.

111 Ding D, Sallis JF, Kerr J, et al. Neighborhood environment and physical activity among youth. Am J Prev Med 2011:41:442-55.

112 Colabianchi N, Clennin MN, Dowda M, et al. Moderating effect of the neighbourhood physical activity environment on the relation between psychosocial factors and physical activity in children: a longitudinal study. J Epidemiol Community Health 2019;73:598-604.

113 Wang L, Tang Y, Luo J. School and community physical activity characteristics and moderate-to-vigorous physical activity among Chinese school-aged children: a multilevel path model analysis. J Sport Health Sci 2017;6:416-22.

114 Liu Y, Tang Y, Cao Z-B, et al. Results from the China 2018 report card on physical activity for children and youth. J Exerc Sci Fit 2019:17:3-7.

115 Kriemler S, Meyer U, Martin E, et al. Effect of school-based interventions on physical activity and fitness in children and adolescents: a review of reviews and systematic update. Br J Sports Med 2011;45:923-30.

116 Heath GW, Parra DC, Sarmiento OL, et al. Evidence-Based intervention in physical activity: lessons from around the world. Lancet 2012;380:272-81.

117 Messing S, Rütten A, Abu-Omar K, et al. How can physical activity be promoted among children and adolescents? A systematic review of reviews across settings. Front Public Health 2019;7:55.

118 Verjans-Janssen SRB, van de Kolk I, Van Kann DHH, et al. Effectiveness of schoolbased physical activity and nutrition interventions with direct parental involvement on children's BMI and energy balance-related behaviors - A systematic review. PLoS One 2018;13:e0204560.

119 Metcalf B, Henley W, Wilkin T. Effectiveness of intervention on physical activity of children: systematic review and meta-analysis of controlled trials with objectively measured outcomes (EarlyBird 54). BMJ 2012:345:e5888.

120 Jones $M$, Defever $E$, Letsinger $A$, et al. A mixed-studies systematic review and metaanalysis of school-based interventions to promote physical activity and/or reduce sedentary time in children. J Sport Health Sci 2020;9:3-17.

121 Xu F, Wang Z, Ye Q, et al. Policy-oriented, school-based physical activity intervention to prevent childhood obesity in China (the health legacy project of the second summer youth Olympic Games): a cluster randomised trial. Lancet Diabetes Endocrinol 2016:4:S9.

122 Feng L, Wei D-M, Lin S-T, et al. Systematic review and meta-analysis of school-based obesity interventions in mainland China. PLoS One 2017;12:e0184704.

123 DiFiori JP, Benjamin HJ, Brenner JS, et al. Overuse injuries and burnout in youth sports: a position statement from the American medical Society for sports medicine. Br J Sports Med 2014;48:287-8.

124 Räisänen AM, Kokko S, Pasanen K, et al. Prevalence of adolescent physical activity-related injuries in sports, leisure time, and school: the National physical activity behaviour study for children and adolescents. BMC Musculoskelet Disord 2018;19:58.

125 Nauta J, Martin-Diener E, Martin BW, et al. Injury risk during different physical activity behaviours in children: a systematic review with bias assessment. Sports Med 2015:45:327-36.

126 Spinks AB, McClure RJ. Quantifying the risk of sports injury: a systematic review of activity-specific rates for children under 16 years of age. $\mathrm{Br} J$ Sports Med 2007:41:548-57.

127 Cai W, Gao Y, Yang W, et al. Physical activity-related injury and its associated factors among middle school students in southern China. Int J Environ Res Public Health 2018:15:1244.

128 Yin MM, Wang SM, Zhuang J. Analysis on sports injuries of adolescents in Shanghai. Chin J Sch Health 2011;32:601-3.

129 Draper CE, Tomaz SA, Biersteker L, et al. The South African 24-hour movement guidelines for birth to 5 years: an integration of physical activity, sitting behavior, screen time, and sleep. J Phys Act Health 2020;17:109-19.

130 Reilly JJ, Hughes AR, Janssen X, et al. GRADE-ADOLOPMENT process to develop 24-hour movement behavior recommendations and physical activity guidelines for the under 5 S in the United Kingdom, 2019. J Phys Act Health 2020;17:101-8.

131 Farooq A, Martin A, Janssen X, et al. Longitudinal changes in moderate-to-vigorousintensity physical activity in children and adolescents: a systematic review and meta-analysis. Obes Rev 2020;21:e12953.

132 Dalene KE, Anderssen SA, Andersen LB, et al. Secular and longitudinal physical activity changes in population-based samples of children and adolescents. Scand J Med Sci Sports 2018;28:161-71. 
133 Lagestad P, van den Tillaar R, Mamen A. Longitudinal changes in physical activity level, body mass index, and oxygen uptake among Norwegian adolescents. Front Public Health 2018:6:97.

134 Faroog MA, Parkinson KN, Adamson AJ, et al. Timing of the decline in physical activity in childhood and adolescence: Gateshead millennium cohort study. $\mathrm{Br} J$ Sports Med 2018;52:1002-6.

135 Metcalf BS, Hosking J, Jeffery AN, et al. Exploring the adolescent fall in physical activity: a 10-yr cohort study (EarlyBird 41). Med Sci Sports Exerc 2015;47:2084-92.

136 Trang NHHD, Hong TK, VAN DER Ploeg HP, et al. Longitudinal physical activity changes in adolescents: HO Chi Minh City youth cohort. Med Sci Sports Exerc 2012:44:1481-9.

137 Kimm SYS, Glynn NW, Kriska AM, et al. Decline in physical activity in black girls and white girls during adolescence. N Eng/ J Med 2002;347:709-15.

138 Telama R, Yang X. Decline of physical activity from youth to young adulthood in Finland. Med Sci Sports Exerc 2000;32:1617-22.

139 Chen P, Mao L, Nassis GP, et al. Coronavirus disease (COVID-19): the need to maintain regular physical activity while taking precautions. J Sport Health Sci 2020;9:103-4.

140 Chen P, Mao L, Nassis GP, et al. Returning Chinese school-aged children and adolescents to physical activity in the wake of COVID-19: actions and precautions. J
Sport Health Sci 2020. doi:10.1016/j.jshs.2020.04.003. [Epub ahead of print: 12 Apr 2020].

141 Sallis JF, Adlakha D, Oyeyemi A, et al. An international physical activity and public health research agenda to inform COVID-19 policies and practices. J Sport Health Sci 2020. doi:10.1016/j.jshs.2020.05.005. [Epub ahead of print: 22 May 2020].

142 Spence JC, Faulkner G, Costas Bradstreet C, et al. Active Canada 20/20: a physical activity plan for Canada. Can J Public Health 2016;106:e470-3.

143 The National Physical Activity Plan Alliance. 2016. US National Physical Activity Plan. Available: https://www.physicalactivityplan.org/docs/2016NPAP_Finalforwebsite.pdf [Accessed 2 May 2020].

144 Department of Health and Children, Health Service Executive. National Physical Activity Plan for Ireland, 2016. Available: https://assets.gov.ie/7563/23f51643fd1d 4ad7abf529e58c8d8041.pdf [Accessed 2 May 2020].

145 National Institute for Health and Clinical Excellence. Choosing health: a physical activity action plan for the UK, 2005. Available: https://www.physicalactivityplan. org/resources/UK.pdf [Accessed 2 May 2020].

146 Rutter H, Cavill N, Bauman A, et al. Systems approaches to global and national physical activity plans. Bull World Health Organ 2019;97:162-5. 